\title{
Education and Research via the Open University Malaysia - An Opportunity for Local Government
}

\section{Siew Nooi Phang}

Faculty of Business and Management

Open University Malaysia

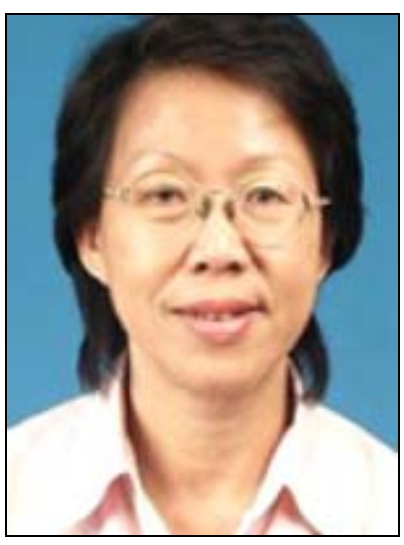

\section{Loo Sze Wei}

Faculty of Business and Management Open University Malaysia

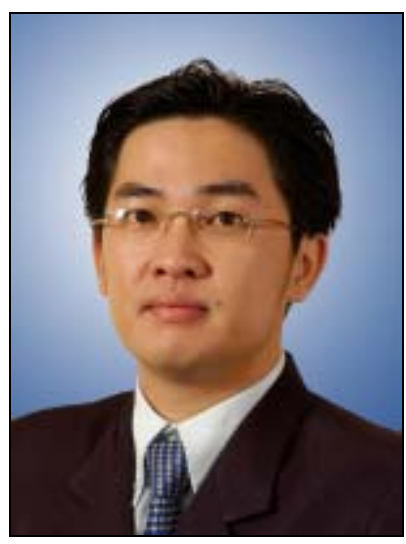

\section{Background}

In this era, the provision of education and dissemination of research-based knowledge need not be restricted to conventional methods such as classroom settings and face-to-face interactions. Advancements in communications via improved technologies enable people from all over the world to seek knowledge to support their needs, conduct global research via 
teleconferencing, and study at their own pace wherever they are and according to their level of ability. Naturally governments, too, are aware of this flexibility to increase their effectiveness and improve the capacity of their staff.

In this context, local government can move towards a more knowledge-intensive and professional entity that can deliver its services more efficiently to the public through open and distance learning. This is especially so for local government in Malaysia where the employees of local authorities may be located in various parts of the country and training via open and distance learning means increased access and flexibility - a combination of work and education without the hassle of having to attend training at a fixed locality. Generally, the Malaysian public is aware of the need for a better quality of life and this has impacted on the services provided by local authorities, which have to be developed and upgraded according to their target groups. Hence local government has to ensure that its workforce is given the support to enhance the quality and relevance of people’s skills. However, using only conventional and existing educational structures may limit the effectiveness and increase the cost of training local government staff. Meanwhile, the Malaysian government is supporting the use of relevant technology to promote innovation and cooperation between departments to upgrade public facilities and services, exchange information, and enhance the skills of employees.

This thinking had already begun during the 1990s when there was a conscious shift towards a knowledge-based economy in Malaysia, as the government realized the need for the country to be competitive and sustainable in line with the global trend of open trade and innovative technology. If Malaysia was to achieve economic growth, it had little choice but to leverage on a workforce that is educated and skilled. This meant that changes had to be made to the country's education structure and policies by placing emphasis on technology: focusing on ICT, broadband networks, the internet and e-government with linkages to the global information highway. Partly the response was to set up more public universities, but it was inevitable that the private sector also had to be involved and given the role of expanding opportunities for education, especially higher education, to anyone who desires it, provided the person possesses the minimum entry requirements. Ultimately, to allow as many people 
as possible and wherever they live or work to gain access to education, the role of the Open University became prominent.

\section{Open University Malaysia - Role and Contribution}

The Open University Malaysia (OUM) was established on the concept of encouraging lifelong learning and providing education using the latest Internet technology, thereby allowing access to education for all. Indeed, OUM was the first open distance learning (ODL) institution in Malaysia. It was set up in 2000 to fulfill the country's aspiration to increase education opportunities for the people, especially working adults ${ }^{1}$. Over the years, ICT and ODL (UNESCO, 2002) have become synonymous with the way OUM operates its programs. Internet technology has increasingly become a fundamental component of learning and delivery of educational materials for OUM’s students (Abu Zarin, et el, 2008). Based on a policy of blended teaching, this allows for limited sessions of face-to-face tutorials with printed learning materials as inputs, alongside online coaching and forum discussions. Thus, OUM's teaching is premised on self-managed learning (80\%), face-toface interaction (8\%) and online learning (12\%) (Abas, Z. W. et al, 2008).

While e-learning allows for freedom in self-learning, it requires much discipline and perseverance. However, OUM has noticed that this strengthens the student's willpower to succeed. Certainly, this makes learning via OUM's methods a dualistic achievement obtaining a degree (knowledge) and character building. Over the years, OUM as an ODL university has developed and fine-tuned its web-education and established a unique system for teaching and learning online. This system enables learners and tutors to interact online where courses and discussions are delivered and carried out digitally. It is known as My Learning Management System (MyLMS). OUM’s MyLMS allows the integration of various features such as instructor and students' guides, technical support, administrative tools and functions, thereby facilitating the teaching and learning process (OUM, 2005). It has given credence to digital education where it is now possible to learn outside the classroom and, importantly, for students to interact with their peers online. It engages both learners and tutors in an environment that permits the transmission of course materials and interaction between different parties who are at various locations all over the country, and globally.

\footnotetext{
${ }^{1}$ OUM was established on $10^{\text {th }}$ August 2000 under the Private Higher Education Institutions Act 1996.
} 
OUM also has in place a library that is fully digital and easily accessed from various destinations in the world, thereby serving the research needs of many of the postgraduate learners who may not reside in Kuala Lumpur where the university is sited.

Video conferencing is a common mode of correspondence and communication, and again this technology has become an integral part of the operations of the OUM. Oral examination or viva-voce for the OUM's $\mathrm{PhD}$ candidates from other countries using video conferencing has made it unnecessary for students to travel to Malaysia for the oral defence of their dissertations. OUM also provides i-tutorial, but this is not used frequently, perhaps due to the popularity and easy accessibility of OUM's other available modes of learning. The underlying concept for the university is that students have a choice to select the most cost effective system that allows them the flexibility they need for learning interaction, whether that be web-based and/or multi-media modes together with printed modules.

As mentioned previously, OUM has developed its own e-learning management systems, namely the MyLMS whereby interaction takes place in an online forum. This opportunity to discuss and interact online would also be of value to local government research, as forums can be accessed easily and allow all those with interest in local government affairs and activities to discuss and share ideas online. Using MyLMS, OUM has already conducted a number of researches on the formation of learning communities to create better learning environments. This is useful in cases where it is not possible to have face-to-face interaction and sharing of information online strengthens research networks. OUM is considering further expansion of this approach with government agencies such as local authorities in order to maximize the potential for learning activities to enhance the skills of staff and benefit local communities. At the same time, research and creative efforts are ongoing to stimulate academic discussion and debate online that transcends both traditional disciplines and geographical boundaries.

\section{Conclusion}

As the OUM works to promote excellence in education, it is conscious of competition from other ODL institutions within Malaysia and globally that seek to offer the same opportunities to a similar pool of potential clients. The trend in education in Malaysia is one of continuous 
growth and development, but OUM will face challenges in terms of technology, politics and economy, demography and market opportunities. Its ability to circumvent the problems that these challenges may pose will depend upon OUM's innovativeness and vision, and its willingness to re-examine and restructure some of its policies in keeping with changing demands and global trends in education.

\section{References:}

Abas, Z W et al., 2008, OUM Tutor’s Handbook, Open University Malaysia, Kuala Lumpur.

Abu Zarin, R et al., 2008, 'The OUM Learning Management System: Evaluating the Effectiveness of Online Forum Discussion for Quantitative Subjects', in Conference Proceeding $8^{\text {th }}$ Annual SEAAIR Conference, Institutional Capacity Building Toward Higher Education Competitive Advantage, 4-6 November, 2008, Surabaya, Indonesia.

Open University Malaysia (OUM) 2005, The Open University Malaysia Learning Management System: A Study of Interaction in the Asynchronous Forum Board, OUM, Kuala Lumpur, accessed 11 June 2009, <http://www.itdl.org/Journal/Nov_05/article01.htm>.

United Nations Educational Scientific and Cultural Organisations (UNESCO) 2002, Open and Distance Learning: Trends, Policy and Strategy Consideration: Executive Summary, UNESCO, Paris, accessed 15 July, 2009,

$<$ http://unescodoc.unesco.org/images/0012/001284/128463e.pdf $>$. 